
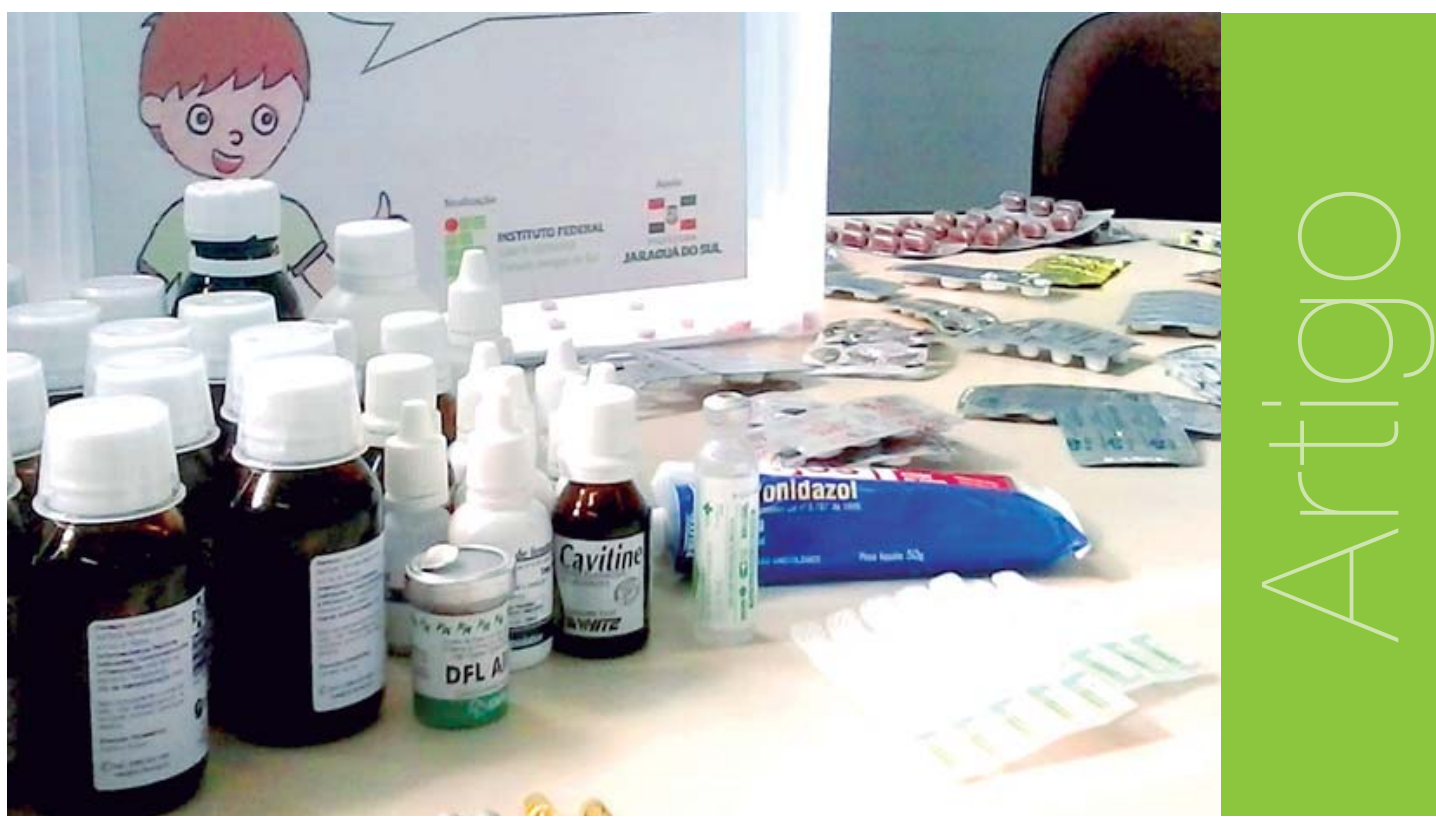

\title{
Análise e Intervenção no Descarte de Medicamentos Vencidos no Município de Jaraguá do Sul
}

\author{
Camila Cecilia Castro1 - caamilah@hotmail.com \\ Carla Karine Bortoli² - caka.bortoli@gmail.com \\ Eduardo Hafemann ${ }^{3}$ - eduardo_hafemann@hotmail.com \\ Júlio Eduardo Bortolini - julioebortolini@gmail.com
}

\section{RESUMO}

0 presente artigo foi desenvolvido por meio do projeto de iniciação à pesquisa científica Conectando Saberes no IFSC do curso técnico integrado em Química, Câmpus Jaraguá do Sul. Em pesquisa, constou que $74 \%$ da amostra coletada no terminal urbano da cidade descarta seus medicamentos de forma inadequada e que a cidade oferece estrutura suficiente para que 0 descarte correto seja efetuado. Então, objetivou-se conscientizar e realizar a divulgação sobre 0 descarte correto de medicamentos vencidos com 0 apoio da prefeitura municipal. Para tanto, ministrou-se palestra aos agentes de saúde da cidade, produziram-se flyers e cartazes informativos e elaboraram-se 10 urnas distribuídas em lugares centrais e periféricos do município. Recolheram-se aproximadamente 18.000 medicamentos, portanto é perceptível que, por meio da integração de mecanismos simples de divulgação, houve uma movimentação significativa da população em direção ao descarte correto dos medicamentos vencidos.

\section{PALAVRAS-CHAVE}

Meio ambiente; Medicamento; Sociedade.

\footnotetext{
1 Estudante do curso técnico integrado em Química do câmpus Jaraguá do Sul do IFSC.

2 Estudante do curso técnico integrado em Química do câmpus Jaraguá do Sul do IFSC.

3 Estudante do curso técnico integrado em Química do câmpus Jaraguá do Sul do IFSC.

4 Professor do curso técnico integrado em Química do câmpus Jaraguá do Sul do IFSC.
} 


\section{ABSTRACT}

This article was developed through scientific research initiation project "Conectando Saberes" in the IFSC Chemistry technician integrated course, Jaraguá do Sul Campus. In research, which comprised $74 \%$ of the sample collected in the urban city terminal discarded their medicines inappropriately and that the city provides enough structure so that proper disposal is made. So, aimed to raise awareness and carry out dissemination on proper disposal of expired drugs with the support of the municipal government. Therefore, it was given a lecture to city health officials, were produced flyers and informative posters and elaborated 10 ballots distributed in central and peripheral parts of the city. They were collected approximately 18,000 medicines, so it is apparent that by integrating simple disclosure mechanisms there was a significant population movement towards the correct disposal of expired medications.

\section{KEYWORDS}

Environment; Remedy; Society.

\section{Introdução}

0 presente artigo é resultado de uma pesquisa (LENTZ et al, 2013) realizada a partir do projeto de iniciação a pesquisa científica "Conectando Saberes" desenvolvido no Instituto Federal de Educação, Ciência e Tecnologia de Santa Catarina - Câmpus Jaraguá do Sul, no curso técnico integrado em Química, e corresponde à aplicação dos conhecimentos adquiridos durante 0 processo de aprendizagem e pesquisa. Após a pesquisa, houve a intervenção na realidade encontrada nesse universo, completando assim os três eixos educacionais propostos pelo curso: ensino, pesquisa e extensão. Esta pesquisa teve como objetivo principal analisar o descarte de medicamentos vencidos no município de Jaraguá do Sul, Santa Catarina, em todo seu processo.

Jaraguá do Sul é uma cidade brasileira localizada no norte de Santa Catarina, com aproximadamente 160 mil habitantes (estimativa IBGE/2014). Possui uma extensão territorial de $529 \mathrm{~km}^{2}$, conta com 24 postos de saúde distribuídos pela cidade, duas farmácias básicas e dois PAMA's (Pronto Atendimento Médico Ambulatorial).

0 ponto de partida da pesquisa foi a Política Nacional de Resíduos Sólidos, atualizada em agosto de 2010. Após a leitura do documento, optou-se por trabalhar com os Resíduos do Serviço de Saúde (RSS). Dentro deste tipo específico de resíduo, selecionou-se o grupo B, correspondente aos "resíduos contendo substâncias químicas que apresentam riscos à saúde pública ou ao meio ambiente, independente de suas características de inflamabilidade, corrosividade, reatividade e toxicidade" (RDC, p.33, 2003). Dentro deste grupo, optou-se ainda por trabalhar com os resíduos que se encaixassem na definição do grupo B1: "resíduos dos medicamentos ou dos insumos farmacêuticos quando vencidos, contaminados, apreendidos para descarte, parcialmente utilizados e demais medicamentos impróprios para consumo, que oferecem risco" (RDC, p. 33, 2003).

Mas de onde surge a necessidade de estudar a questão do descarte de medicamentos vencidos? Como sabemos, os fármacos têm um papel inquestionável em nossa sociedade. Calixto e Siqueira (2006) nos falam que desde os primórdios da civilização, a procura pelo tratamento das principais doenças que acometem a humanidade tem sido uma preocupação constante da população.

Nota-se, então, que 0 manuseio e manipulação dos recursos naturais não apresentavam nenhum risco ao bem estar do ser humano ou do meio ambiente, já que inicialmente os produtos medicamentosos tinham origem natural e eram utilizados de acordo com as necessidades dos pacientes, não sendo manipulados ou produzidos em massa. Porém, ao aumentar sua capacidade de ajuste e intervenção, 0 homem modifica também 0 ambiente onde vive. Naime, Sartor e Garcia (2005) observam que quando a população humana era pequena e a natureza tinha como compensar os impactos a que era submetida, não ocorriam desequilíbrios.

Vivemos em um mundo onde a tecnologia e o consumo representa o modo de vida da sociedade atual. Se por um lado o avanço tecnológico possibilita a solução de problemas que limitavam a vida do ser humano, por outro, nos deparamos com problemas recentes, decorrentes do 
processo de globalização e da consolidação da sociedade de consumo. Um desses problemas é a geração de resíduos, fruto do consumo excessivo que caracteriza o modo de vida capitalista. Como defende Ferreira (1995), nossa civilização chega ao limiar do século XXI como a civilização dos resíduos, marcada pelo desperdício e pelas contradições de um desenvolvimento industrial e tecnológico sem precedentes na história da humanidade. Levando em consideração ainda a complexidade dos medicamentos hoje elaborados e a crescente expansão do mercado farmacológico, tanto em termos de produção quanto em termos de consumo, é imprescindível que 0 descarte correto destes produtos seja efetuado.

Segundo Monte (2010), o varejo de medicamentos no Brasil apresenta peculiaridades específicas, pois existem ao total 48 mil farmácias no país, considerado o dobro do necessário pela Organização Mundial de Saúde (OMS). A indústria farmacêutica brasileira, em 1998, faturou cerca de US $\$ 10,31$ bilhões e 12 anos depois seu faturamento chegou a US $\$ 20,6$ bilhões, dobrando 0 seu faturamento. Em 2006 vendeu-se aproximadamente 1,43 bilhões de medicamentos no Brasil e em 2010 esse valor já chegava a 2 bilhões. Um crescimento de aproximadamente 44,06\% (IMSHEALTH, 2008). Percebe-se que 0 mercado farmacêutico é lucrativo e vende quantidades gigantescas de medicamento em nosso país. Uma questão importante a ser reconhecida é o destino desses.

Devido ao consumo exacerbado de medicamentos, Bila e Dezotti (2003) trazem à tona uma questão a ser considerada sobre 0 assunto. As autoras afirmam que independente da fonte geradora dos resíduos de fármacos, medicina humana, veterinária ou indústrias, estes resíduos acabarão, em algum momento, sendo depositados no solo e nas águas, podendo influenciar na qualidade destas matrizes e na saúde ambiental como um todo. Traços de várias espécies de medicamentos estão sendo detectados em afluentes. Os maiores problemas encontrados, em relação a essas concentrações, estão no desenvolvimento à resistência bacteriana aos antibióticos e avaliações de perturbação no sistema endócrino por substâncias como estrogênios. Infelizmente, outros efeitos possíveis têm sido pouco investigados, porém já se percebe danos causados por tipos de medicamentos em seres vivos.

Diante da atualidade e importância sobre fármacos em nosso meio social e ambiental, foi elaborada a seguinte questão problema: quais são ações tomadas quanto ao descarte de medicamentos vencidos em Jaraguá do Sul, por parte da iniciativa privada e do poder público? E qual a sua abrangência para com a população?

A pesquisa teve como objetivo principal estudar as ações tomadas por parte do poder público e privado, bem como seu embasamento legal e sua abrangência com os cidadãos jaraguaenses. Para tanto, os objetivos específicos elencados foram: analisar 0 descarte de medicamentos vencidos, de acordo com a RDC no 33 de 2005, e outras legislações vigentes; averiguar as semelhanças e diferenças dos programas de coleta de medicamentos vencidos da cidade em questão com os de outras cidades; entrevistar o setor público responsável pela parte de distribuição e coleta de medicamentos e as farmácias privadas que disponibilizam meios para 0 descarte de medicamento vencido em Jaraguá do Sul e, por fim, averiguar a abrangência das ações do poder público e privado para com a população.

Por fim, após a pesquisa, interviu-a no universo pesquisado por meio da divulgação do descarte de medicamentos vencidos para população jaraguaense e a conscientização do maior número possivel de munícipes para o descarte adequado dos medicamentos vencidos ou fora de uso, contando com o apoio da prefeitura municipal.

\section{Metodologia}

Para alcançar os objetivos da primeira parte do projeto, fez-se a leitura das resoluções vigentes que tratam das diretrizes técnicas do gerenciamento, transporte e acondicionamento de resíduos, bem como sobre seu descarte; leram-se também outros projetos de outras cidades, identificando assim a metodologia aplicada e outras questões que servissem para fazer um paralelo à realidade municipal. 
Fez-se entrevistas pré-estruturadas com perguntas relativas à triagem, divulgação e embasamento legal de três instituições que recolhem medicamentos vencidos, sendo uma delas de ordem pública e as outras duas de ordem privada, a fim de constatar a realidade da cidade quanto às tomadas frente ao descarte de medicamentos vencidos. Aplicou-se aproximadamente 600 questionários no terminal urbano da cidade em 2012, e, em 2013, realizou-se 190 questionários online para com a população jaraguaense a fim de constatar a abrangência dessas iniciativas.

Constatando os pontos fracos e fortes de todo o sistema de coleta na cidade de Jaraguá do Sul, seguiu-se para a segunda parte do projeto, a intervenção, que tem como principal enfoque a divulgação e a conscientização. Para tanto, buscou-se abranger a população geral por meio dos agentes de saúde, elo entre população e Unidades da Saúde.

Por meio da ministração de palestras e da criação e distribuição de cartilhas pela equipe executora do projeto (IFSC, 2014) aos agentes de saúde da região, buscou-se convence-los de sua importância social no recolhimento de medicamentos vencidos nas residências, elucidando fatos sobre o descarte de medicamentos vencidos, expondo resultados obtidos por meio da pesquisa.

Elaborou-se também uma estratégia de divulgação e recolhimento que aliou ações simples, informação e difusão de conhecimento por meio da produção de flyers e cartazes informativos e de urnas para recolhimento dos medicamentos vencidos. Houve a fixação de cartazes no interior dos ônibus que circulam no município de Jaraguá do Sul, bem como nas unidades de saúde. Buscando ainda um estímulo que, além do verbal e visual, criasse um vínculo de comprometimento e convidasse o público a descartar seus medicamentos de forma correta, elaborou-se uma urna com adesivo contendo informações sobre o descarte correto.

Procurou-se obter uma maior abrangência da população e eficiência na ação, distribuiu-se nove urnas em cinco postos de saúde - localizados em bairros centrais e periféricos da cidade, bem como nos dois PAMAs (Pronto Atendimento Médico Ambulatorial) e nas duas farmácias básicas da cidade. É importante ressaltar que mesmo as unidades de saúde não contempladas com urna receberam material de divulgação. Salientam-se que todas as unidades de saúde do município captam os medicamentos, tendo ou não as urnas de coleta.

\section{Resultados e discussões}

Utilizando um roteiro pré-estruturado que continha questões sobre divulgação, coleta dos medicamentos no local e triagem, aplicou-se entrevistas no setor público responsável pela distribuição e coleta de medicamentos da cidade, assim como em dois outros estabelecimentos de iniciativa privada que dispunham do serviço de coleta de medicamentos vencidos. Escolheram-se esses estabelecimentos por terem sistemas "formais" com urnas e alguma divulgação anterior na cidade.

Percebeu-se por meio das entrevistas uma grande discrepância entre o sistema público e privado. A primeira grande diferença está no uso de legislação. Enquanto o sistema privado I utiliza-se de uma diretriz bastante atualizada, o sistema privado II se utiliza das mesmas resoluções vigentes apontadas na PNRS (Politica Nacional de Resíduos Sólidos). Já o setor público, mesmo tendo suporte interno da vigilância sanitária, não mencionou utilizar nenhuma legislação, apesar de conhecer os mecanismos legais que regem essa questão.

Revelou-se que alguns dos medicamentos recolhidos pelo sistema público, se estiverem dentro do prazo de validade ou com bom aspecto físico, são doados a outras pessoas. É importante ressaltar que ao se retirar o medicamento da caixa, automaticamente o prazo de validade do produto é alterado, visto que condições como temperatura, umidade do ar e outras variáveis podem ocasionar a alteração do produto e uma possível diminuição em sua eficácia. Por estes motivos, esta prática não é aconselhável.

Em relação ao recolhimento dos resíduos, é percebido que todo o processo se dá através de uma terceirização excessiva, onde uma empresa efetua o recolhimento do medicamento e 0 
transporta até outra empresa que irá armazenar este resíduo, e por sua vez, irá depois contratar outra empresa para então tratá-lo de alguma forma, através da incineração ou o depósito em aterros especiais para este tipo de produto.

Como consequência, quando os entrevistados eram questionados sobre o destino dos medicamentos após serem recolhidos pelas empresas, percebia-se certa dificuldade em realmente saber tudo o que acontecia; pois a quantidade de empresas envolvidas era tão grande que 0 sistema de coleta não era compreendido corretamente por todos os locais que aqueles resíduos passava, sendo que somente o sistema privado tinha consciência do destino final dos mesmos, ao contrário da partição pública.

Essa também é uma dúvida que permanece, se as empresas contratadas pelo setor privado realmente destinam esses resíduos de forma correta ou não, tendo em vista que a maioria das empresas é de outras cidades e até estados. Lembrando que, se o resíduo não for tratado de forma correta, ainda há possíveis impactos no meio natural e na vida dos seres humanos, muito bem ressaltados em trabalhos de Bila e Dezotti (2003); onde constata-se maior resistência bacteriana aos antibióticos em águas isoladas nas propriedades rurais. Portanto, torna-se imprescindível que se tenha consciência de toda a triagem dos medicamentos, para que se possa efetivamente descartá-los de forma correta.

Em leituras de projetos de outras cidades, percebeu-se uma grande diferença no foco das iniciativas. Em Criciúma-SC (BERNARDO, 2009) e Curitiba-PR (AZEVEDO, 2001), a questão da coleta de medicamentos vencidos é complementar a um contexto maior. No caso de Curitiba, por exemplo, a coleta se dá juntamente com outros materiais que não são descartados nem no lixo orgânico nem no reciclável, o que facilita a formação do hábito de descartar os resíduos domiciliares especiais, não somente os medicamentos.

Em Jaraguá do Sul, percebeu-se que a questão é tratada de forma diferente, pois as iniciativas não estão inseridas em um contexto maior ou relevante, são tratadas apenas como complementos dos serviços oferecidos por algumas farmácias e pela iniciativa pública.

Observou-se que a iniciativa pública foca-se na questão social do problema, devido à intoxicação ocasionada pela ingestão de medicamentos vencidos, enquanto a iniciativa privada foca-se no meio comercial, onde a coleta de medicamentos vencidos passa a imagem de comprometimento com o meio ambiente, sendo um diferencial que contribui positivamente para a sua imagem. Observando as três iniciativas pesquisadas em Jaraguá do Sul, é possível perceber que nenhum dos sistemas consegue abranger totalmente a cidade.

Dessa forma, nota-se que para atingir a maior parte a população jaraguaense, os dois sistemas, público e privado, teriam que trabalhar de forma unida e conjunta. 0 sistema público poderia intensificar seu trabalho nos bairros ao longo da cidade e o sistema privado poderia intensificar suas ações no centro da cidade, tornando assim acessível a toda a população o descarte de medicamentos vencidos, sem grandes problemas com locomoção ou falta de informação sobre o descarte. Como observado no parágrafo anterior, essa união entre público ocorre nas duas cidades pesquisadas, relacionando-se a um contexto maior e atingindo assim a população.

Outra questão a ser discutida é a abrangência desses sistemas. Os dados obtidos por meio dos questionários, que foram elaborados pela equipe e divulgados online (Figura 1b) em março de 2013, atingindo um total de 190 pessoas, sendo que 142 foram utilizados e o restante foi descartado. Os dados elucidam a ineficiência da divulgação desses sistemas, onde o que mais chama a atenção é o fato de 88,8\% dos entrevistados declararem não conhecer nenhum tipo de sistema de coleta de medicamentos vencidos em Jaraguá do Sul.

Os questionários utilizados na primeira fase desse trabalho foram aplicados em dezembro de 2012, sendo que um total de 619 pessoas foram entrevistadas no terminal urbano da cidade. Quando indagadas sobre o conhecimento de alguma ação/campanha de coleta de medicamentos, percebeu-se que a maioria da população não conhece qualquer sistema de coleta de medicamentos. Tanto que em ambos os questionários, 2012 e 2013, se repetiu 0 mesmo resultado. 
7.Você tem conhecimento de algum programa de coleta de remédios?(2012)

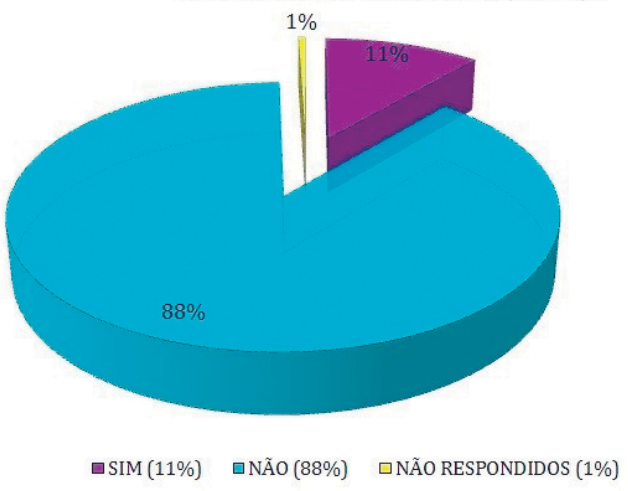

4. Você conhece alguma ação/campanha de coleta de medicamentos vencidos? (2013)

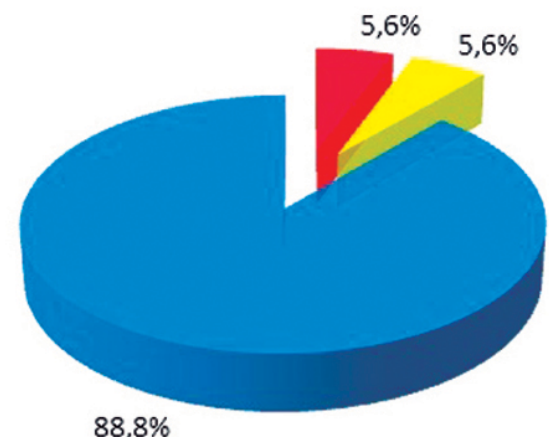

do questionário 2013.

$88,8 \%$

Fonte: Dados desta pesquisa.

—Sim (Iniciativa pública) $(5,6 \%) \quad$ Sim (Iniciativa privada) $(5,6 \%)$ — Não $(88,8 \%)$

0 mesmo aconteceu com as formas de descarte. Pode-se concluir que se obtiveram resultados semelhantes em ambos os levantamentos nas mesmas questões e, o mais importante, é que esses dados apontam que a maior parte da população de Jaraguá do Sul descarta medicamentos vencidos no lixo comum. 0 gráfico da Figura 2a mostra que 65,6\% da amostra pesquisada descarta seus medicamentos no lixo comum, pia, vaso sanitário e outras formas incorretas de descarte; enquanto 0 gráfico da Figura 2b (questionário online) mostra que 68,8\% descarta os medicamentos de forma errônea, sendo que a parcela da população que descarta os medicamentos de forma correta fica em 19,2\% na Figura 2a e em 9,9\% na Figura $2 b$.

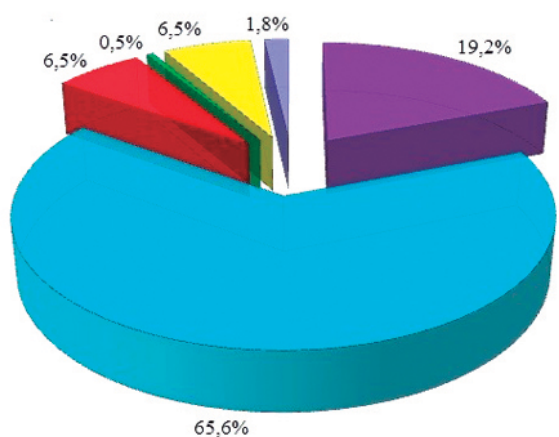

口Devolve a unidade $(19,2 \%)$

घNão Sobra $(6,5 \%)$

$\square$ Joga no lixo $(65,6 \%)$

a Guarda $(0,5 \%)$

$\square$ Descarta no vaso sanitário $(6,5 \%)$ 口 Outros / Não responderam $(1,8 \%)$ 


\section{Você já descartou medicamentos vencidos?}

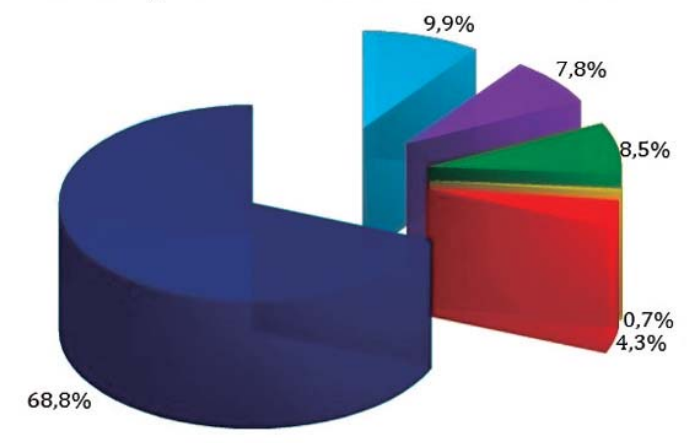

- Descartam no lixo $(68,8 \%)$ = Descartam na pia/vaso sanitário $(4,3 \%)$ Queima $(0,7 \%)$

= Guarda $(7,8 \%)$ n Não sobra $(8,5 \%)$

$=$ Devolvem ao local correto $(9,9 \%)$
Figura 2b: Pergunta número 3

do questionário 2013.

Fonte: Dados desta pesquisa.

Dessa forma, pode-se observar a pouca abrangência desses sistemas, bem como a falta de conscientização da população jaraguaense sobre 0 assunto. Foi baseado nessas discussões que o projeto de extensão teve como objetivo intervir no universo pesquisado e realizar a divulgação e a informatização dos pontos de coleta.

Após toda a coleta de dados inicial, percebeu-se que a falta de informação era uma das principais causas do descarte incorreto de medicamentos em Jaraguá do Sul. Tendo em mente o principal problema, pode-se tomar providências de forma mais consciente, sabendo realmente onde e como agir.

A partir deste momento, foi contatado o serviço público de saúde da cidade para iniciar uma parceria, entre os alunos do Instituto Federal de Santa Catarina e o setor mencionado. Essa parceria consistia em abrir as portas para os estudantes, a fim de construir métodos de divulgação na cidade sobre o descarte de medicamento.

Primeiramente realizou-se uma palestra aos agentes de saúde. Em geral foi receptiva, sendo que 0 grupo ouviu atentamente, apesar de alguns grupos isolados demonstrarem um pouco de indisposição. Existiu um pequeno debate onde uma das agentes afirmou não ser sua atribuição recolher os medicamentos, e sim orientar as pessoas sobre o destino correto. Ela chamou atenção para criação de um hábito que acomodaria as pessoas. Ainda segundo ela, se os agentes não passarem nas casas recolhendo, os cidadãos irão continuar a descartar os medicamentos de forma errônea. Conscientizar mostra a grandeza desse ato e também insere os cidadãos de forma efetiva na campanha, segundo ela.

Houve uma tréplica de outra agente que disse não ver problema em recolher os medicamentos, apesar de saber que seu trabalho não se resume a "catar remédio". Ela acha que a ação é importante e "não custa nada". Neste ponto, chamou-se atenção para casos onde pessoas com doenças crônicas elou infecciosas falecem e deixam seus medicamentos, ou ainda, de uma parte da população idosa que não sai de casa com muita frequência.

Alguns agentes afirmaram "já realizar o trabalho de orientação". Mesmo apesar dos impasses e dúvidas dos agentes, aparentemente foi possível instruí-las um pouco e criar uma parceria, entre o nosso método de divulgação e os agentes. Por fim, convidou-os a retirar medicamentos vencidos das residências que visitavam, a fim de evitar o descarte incorreto e a possível intoxicação em caso de ingestão.

Após a elaboração de flyers e cartazes, ocorreu a implantação das urnas (Figura 3) e, posteriormente, 0 jornal local publicou uma reportagem sobre 0 assunto. A confecção dos flyers e cartazes foi feita no intuito de elaborar um material que já remetesse ao assunto e que tentasse passar sua mensagem por meio de desenhos e pouca escrita, tendo assim como objetivo principal compartilhar a informação de uma forma simples e rápida, como elucidado a seguir (Figura 4). 
Figura 3: Urnas distribuídas aos postos de saúde.

Figura 4: Flyer e Cartaz, que levavam as mesmas ilustrações e mensagens.

Fonte: Dados desta pesquisa.
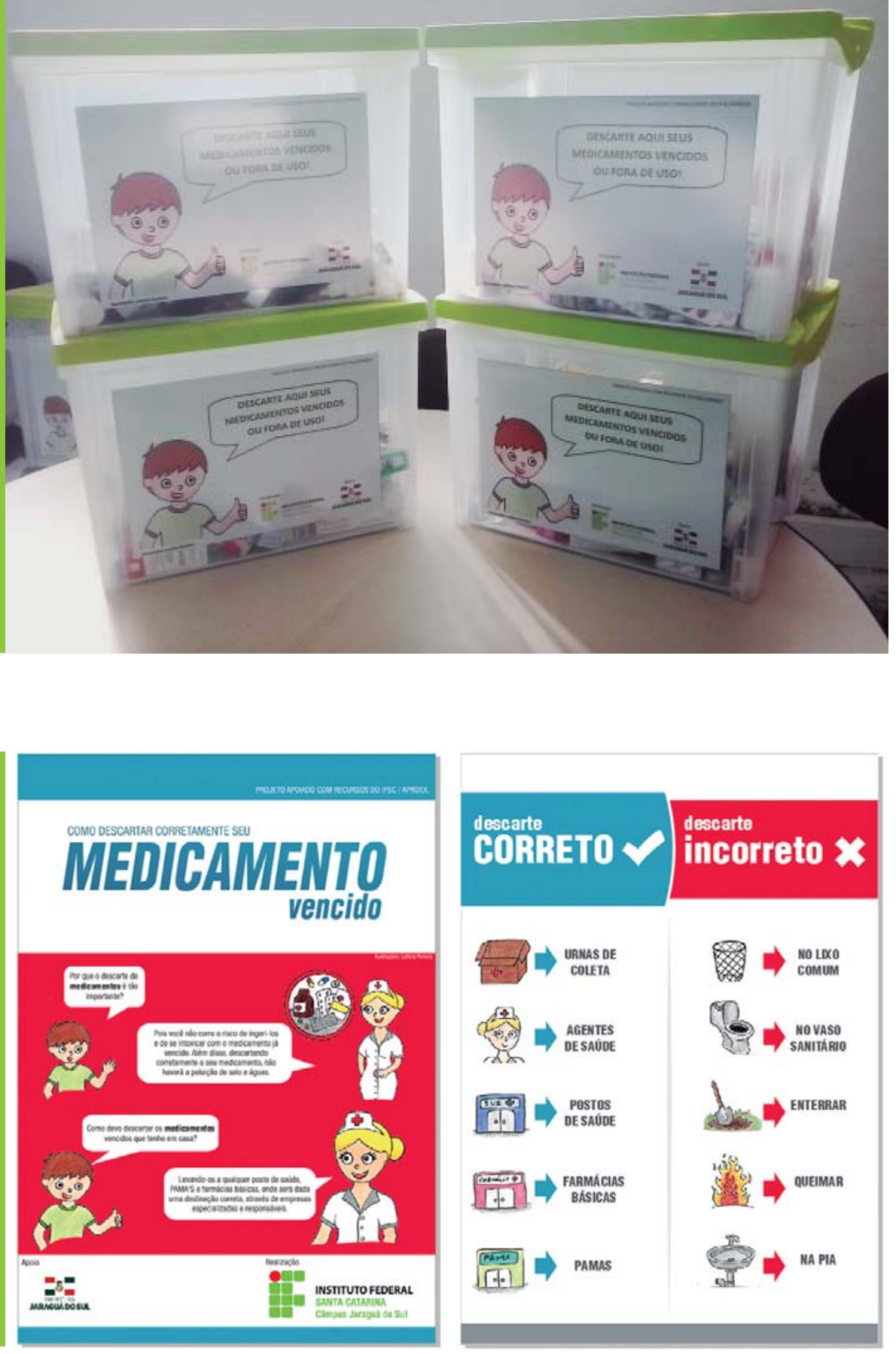

descarte
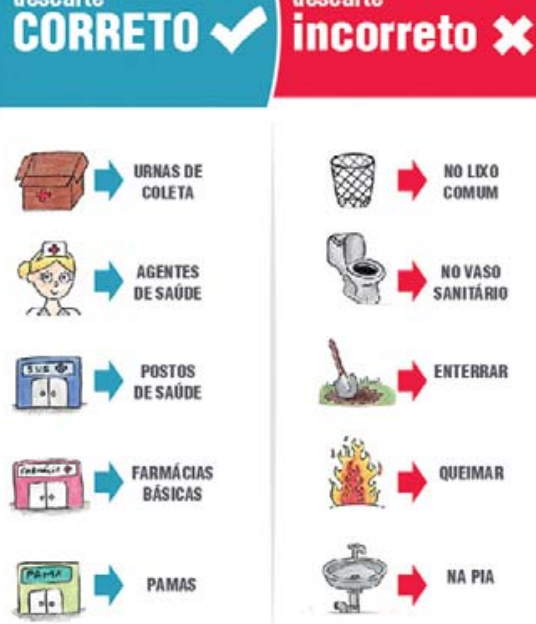

wis
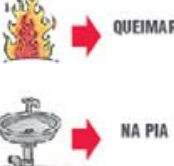

Foram distribuídos aproximadamente quatro mil flyers aos agentes de saúde para serem distribuídos às famílias. Além disso, todos os 21 postos de saúde da cidade receberam uma quantia de aproximadamente 60 flyers e um ou dois cartazes. Foram colocados 14 cartazes dentro de ônibus da cidade e mais 50 cartazes em estabelecimentos comerciais e nos dois hospitais, e também, no próprio Instituto Federal de Santa Catarina (IFSC).

No dia 20 de maio, nove unidades de saúde foram contemplados pelas urnas confeccionadas pela equipe (Figura 3). A urna permaneceu exposta para visualização da população que circulava no local, e acompanhando a urna, foi disponibilizado o cartaz e os flyers. A urna permaneceu à disposição até dia 31 de julho. Nesse tempo, foram feitas duas coletas. A primeira, dia 02 de julho, recolhendo apenas os medicamentos, e a segunda coleta dia 31 do mesmo mês, só que desta vez, retirando também a urna do local para quantificação. As informações em relação à primeira e segunda quantificação estão contidas no quadro a seguir: 


\begin{tabular}{|l|c|c|}
\hline \multicolumn{1}{|c|}{ Produtos recolhidos } & Primeira Coleta & Segunda Coleta \\
\hline Comprimidos & 9370 & 6641 \\
\hline Frascos & 228 & 190 \\
\hline Pomadas & 41 & 28 \\
\hline Comprimidos Fracionados & 1165 & 497 \\
\hline Ampolas & 20 & 0 \\
\hline Saches & 4 & 31 \\
\hline Outros (kits, camisinhas, bombinhas) & 16 & 5 \\
\hline Total & $\mathbf{1 0 8 4 4}$ & $\mathbf{7 3 9 2}$ \\
\hline
\end{tabular}

Quadro 1: Quantificaçãa

dos medicamentos e itens

recolhidos nas urnas.

Fonte: Dados desta pesquisa.

A primeira coleta se estendeu por um período de aproximadamente 32 dias e foram coletados 9.370 comprimidos encapsulados e também um número considerável de outros itens. Já a segunda coleta se estendeu por um período menor, em torno de 21 dias, e foram coletados 6.641 comprimidos e também, outra grande gama de outros medicamentos.

Pode-se observar através dos dados obtidos com a intervenção, um recolhimento de medicamentos considerável, mesmo sem dados anteriores para ser realizada comparação da quantidade recolhida antes e pós-urna, pode-se perceber que essencialmente a urna fez efeito sobre a quantidade recolhida. Fica claro, portanto, que os cidadãos se mostraram dispostos a depositar seus medicamentos nas urnas, mostrando-se adeptos à campanha. Contudo, não se pode afirmar que os flyers e cartazes distribuídos tiveram influência nesses recolhimentos, mas se tem certeza que a urna, para o descarte de medicamento nos postos de saúde, produz uma reação positiva nas pessoas, sendo aparentemente convidativa e confortável aos cidadãos que ali frequentam depositarem seus medicamentos vencidos.

A urna não é apenas uma forma de convidar as pessoas a depositarem seus medicamentos, mas também, uma forma de relembrar o cidadão que o descarte pode ser feito neste lugar. Em uma conversa com a enfermeira do posto de saúde de um dos bairros, foi relatado que o projeto foi realmente bom para a comunidade. Muitas pessoas começaram a trazer seus medicamentos e após a retirada da urna, foi sentido falta da mesma, assim movimentou até os próprios funcionários do posto a elaborar uma pequena caixa para o recolhimento dos medicamentos; mostrando que a movimentação e conscientização não se deram apenas por parte da população e sim também por todos envolvidos ao redor dela, de cidadãos comuns, até os servidores públicos que mantêm a intenção de continuar com as urnas. Em geral, o método de divulgação se mostrou efetivo e bem recebido, indicando que houve certa receptividade da população em relação às urnas e 0 assunto.

Enfim, sabe-se que este projeto, em geral, só atingiu uma parte da população. Ainda existem os inúmeros cidadãos que frequentam e consomem medicamentos nas farmácias particulares pela cidade. Então, como a utilização de urnas se mostrou eficiente nas unidades públicas, se compreende que 0 sistema de coleta pode ser expandido também para outros locais, abrangendo assim a maior parte da população jaraguaense. Essa questão traz à tona 0 aspecto cultural que perpassa o descarte correto dos medicamentos e a necessidade de conscientização e sensibilização quanto à questão.

A partição pública mostrou-se consciente desse aspecto, comentando sobre ele durante as entrevistas e demonstrando interesse na questão, tendo ainda um setor exclusivo para a educação em saúde, onde são visadas ações que promovam a sensibilização e conscientização da população quanto à questões de saúde por meio de palestras em escolas, associação de moradores, postos de saúde e outros meios.

Na leitura das leis e diretrizes técnicas, percebeu-se também que o gerenciamento dos RSS mostra-se relevante no meio social, uma vez que esses insumos, se descartados incorretamente, interferem drasticamente no meio ambiente. Percebeu-se que, em nível de legislação, o Brasil caminha para uma estruturação, apresentando diretrizes técnicas. Porém, 
algumas são desatualizadas e a maioria não inclui o consumidor na cadeia de responsabilidade pelo descarte de medicamentos.

Segundo as autoras Bila e Dezoti (2003), o problema ambiental causado pelo descarte incorreto dos medicamentos mostra que deve se ter uma preocupação em reverter ou ao menos amenizar o impacto dos medicamentos no meio ambiente, não implicando somente em um gerenciamento do descarte de medicamentos vencidos ou mesmo no estudo dos metabólitos, e sim na questão de seu consumo. Como mostrado em uma parte do trabalho, o Brasil é um dos maiores consumidores de fármacos do mundo, e esse índice só tende a crescer.

Segundo o relatório "Antimicrobial resistance: Global Report on Surveillance" da ONU, em 2014, em alguns anos podemos viver uma era pós-antibióticos, onde doenças que eram tratadas por décadas podem voltar a matar novamente. Um dos pilares da medicina moderna são os antibióticos e seu uso indiscriminado e de maneira errônea pode levar à sua própria ruína. Está contido no relatório que sete tipos de bactérias comuns e graves estão começando a possuir certos níveis de resistência aos antibióticos que causam doenças como: diarréia, pneumonia, infecção urinária, gonorreia etc. Esse panorama é visualizado em todo o mundo.

Pode-se observar que os resíduos B1, segundo a legislação, podem ser jogados na rede de esgoto sanitário, mesmo que sejam antibióticos. Essa questão é preocupante, visto que, como afirma reportagem da revista Vida e Saúde (2010) "esses produtos acabam com microrganismos menos fortes, deixando vivos apenas os mais resistentes. Assim, uma bactéria presente em um rio que contenha traços de antibióticos pode adquirir resistência a essas substâncias", afirmam os autores da reportagem. Nascimento (2008, apud Araújo e Hoppe, 2012) salienta que os remédios possuem componentes resistentes que não são totalmente removidos pelo sistema de tratamento convencional de água. Sendo assim, se estes não forem destinados de forma correta e consciente por todas as partes, há a possibilidade de retornarem ao próprio cidadão que 0 descartou, através da rede de abastecimento de água, caracterizando uma ingestão indireta dessa substância química, o que torna essencial o seu descarte adequado. Além disso, sabemos que até mesmo um xarope pode conter cafeína, e que essa não é retirada da água com os tratamentos convencionais utilizados para tratar a água captada, chegando até as nossas casas.

João (2011) defende que o descarte indevido de medicamentos é um dos grandes causadores da contaminação do meio ambiente, sendo necessário realizar um gerenciamento dessa espécie de resíduo para amenizar o problema. Essa contaminação é resultado de uma série de fatores, como o descarte incorreto de medicamentos, metabólitos excretados que não são retirados no tratamento de esgoto e também medicamentos de uso veterinário.

Segundo João (2011) foram identificados 36 fármacos diferentes em diversos rios, na Alemanha, dentre os quais estão: antilipidêmicos, analgésicos-antipiréticos, anti-inflamatórios e antihipertensivos. De forma preocupante, no Reino Unido, estudos realizados revelaram a presença de fármacos em concentrações maiores que um micrograma por litro no meio aquático.

Analisando os quadros com a relação de medicamentos recolhidos nas duas coletas, percebese que Jaraguá do Sul está gerando uma enorme quantidade de contaminantes e principalmente fármacos anti-hipertensivos.

Quadro 2: Cinco

medicamentos mais

recolhidos na primeira coleta.

\begin{tabular}{|l|c|c|c|}
\hline \multicolumn{4}{|c|}{ COMPRIMIDOS DA PRIMEIRA COLETA } \\
\hline Princípio ativo & Medicamento & Função & Quantidade \\
\hline Metildopa & Venopressin/Metilvita/Tensioval & Anti-hipertensivo & 979 \\
\hline Hidroclorotiazida & $\begin{array}{c}\text { Diuretic/Hidromed/Clorana/ } \\
\text { Hidrolan/Hidroless }\end{array}$ & Anti-hipertensivo & 336 \\
\hline Prometazina & Cloridrato De Prometazina & Antialérgico & 320 \\
\hline Glimepirida & Betes & Antidiabético & 315 \\
\hline Prednisona & Corticorten /Prednisona/Meticorten & Anti-Inflamatório & 254 \\
\hline
\end{tabular}




\section{COMPRIMIDOS DA PRIMEIRA COLETA}

\begin{tabular}{|l|c|c|c|}
\hline Princípio ativo & Medicamento & Função & Quantidade \\
\hline Nifedipino & Nioxil & Anti-hipertensivo & 327 \\
\hline Hidroclotiazida & Diuretic/Hidromed/Clorizin/Diuriz & Anti-hipertensivo & 285 \\
\hline $\begin{array}{l}\text { Besilato de } \\
\text { Anlodipino }\end{array}$ & Amlodil/Besilapin/Roxflan 5 & Anti-hipertensivo & 276 \\
\hline $\begin{array}{l}\text { Maleato de } \\
\text { Enalapril }\end{array}$ & Enaiprim/Enalamed/Pressomede & Anti-hipertensivo & 268 \\
\hline Captopril & Captopril/Hipoten & Anti-hipertensivo & 239 \\
\hline
\end{tabular}

Constata-se, diante destes quadros, que a população jaraguaense é ávida consumidora de fármacos anti-hipertensivos, caracterizando problemas em relação a sua alimentação e modo de vida, resultando em uma elevado consumo desses fármacos. Diante disso, há uma alta geração de contaminantes, tanto como metabólitos, medicamentos descartados que provavelmente teriam o destino do lixo comum, segundo a pesquisa realizada.

Então é possível fazer um paralelo entre os fármacos encontrados nos rios da Alemanha, citado por João (2011), e os encontrados na região de Jaraguá do Sul. Provavelmente devido ao grande número de anti-hipertensivos, os recursos hídricos podem estar contaminados com esses fármacos, entretanto não se sabe a concentração. Mas pode-se afirmar que é o medicamento mais descartado de nossa região, pois dentre os 10 medicamentos mais recolhidos nas duas coletas, sete deles são anti-hipertensivos, ou seja, há um grande consumo e um grande descarte desse fármaco no município.

Atualmente, não foram realizados estudos profundos sobre possíveis danos em relação à essa espécie de fármaco como contaminante. Entretanto, devemos ficar em alerta, pois mesmo ainda não conhecendo os riscos, medidas devem ser tomadas, a fim de evitar problemas de saúde pública no futuro.

No Brasil, a questão do descarte de medicamentos reveste-se de importância única devido à carência de políticas públicas sobre o tema, bem como aos baixos índices em tratamento de esgoto, principal vetor de contaminação de águas superficiais e subterrâneas utilizadas como fontes de abastecimento público. Dessa forma, esses contaminantes não estão incluídos em monitoramentos de órgãos da saúde e do meio ambiente, e como significado emergente tem como referência a preocupação com essas novas substâncias e sobre seus reais impactos tanto para a saúde humana quanto o risco para 0 meio ambiente, englobando substâncias que são utilizadas há tempo, como também as que são descobertas decorrentes dos avanços tecnológicos. 0 que salienta a importância de uma observação mais meticulosa da lei que deve passar por processos periódicos de atualização e melhoramentos.

\section{Conclusões}

Durante a revisão bibliográfica, verifica-se que a questão da contaminação de recursos naturais ainda é pouco estudada, sendo que não existem pesquisas conclusivas sobre seu impacto, fato que caracteriza esse tipo de resíduo como emergente. Desta forma, percebe-se que a questão do consumo seja tão, ou talvez até mais relevante, que a questão do próprio descarte, visto que o medicamento que é consumido sem necessidade ou comprado a esmo pode vir a passar do prazo de validade e ser descartado de forma incorreta.

Percebeu-se que o contexto social interfere na questão do descarte de medicamentos vencidos, uma vez que 0 cidadão que não é sensibilizado com a questão e, pelos mais diversos motivos, oferece resistência às informações dadas, não efetuará o descarte de medicamentos nos pontos de coletas e sim no lixo comum, na rede de tratamento fluvial ou ainda de alguma outra forma
Quadro 3: Cinco

medicamentos mais

recolhidos na segunda coleta.

Fonte: Dados desta pesquisa. 
que seja prejudicial ao meio em que vivemos. Dessa forma, considera-se que esforços devem ser feitos no sentido de divulgar os pontos de coleta, bem como a forma ideal de descartar os medicamentos, sensibilizando a população quanto à importância do mesmo e incentivando sua participação.

Considera-se ainda que essa sensibilização deva ser um fator a ser trabalhado em todo e qualquer projeto que envolva a questão, sensibilização essa não somente no âmbito ambiental do descarte de resíduos, mas também no âmbito comercial, despertando a consciência de que, ao comprar um produto que tem prazo validade, esse deverá ser descartado pelo próprio consumidor que 0 adquiriu.

Notou-se que o município de Jaraguá do Sul apresenta estrutura para que os medicamentos não consumidos sejam descartados, mas que a divulgação deficiente desses mecanismos e a falta de coordenação fazem com que a questão não seja abrangida em sua totalidade, tornando os sistemas atuais ineficientes.

Em vista das considerações sobre a necessidade de divulgação de um descarte correto dos medicamentos vencidos, a elaboração de materiais, da palestra ministrada e das visitas feitas às unidades de saúde que receberam as urnas, mostraram-se eficientes, movimentando a população quanto ao descarte correto dos medicamentos. Não apenas por parte da comunidade, pois se observou também 0 envolvimento dos agentes de saúde e dos responsáveis pelas unidades de saúde, mesmo alguns se mostrando resistentes inicialmente.

A eficiência fica clara quando observa-se que 18 mil comprimidos foram recolhidos em apenas 53 dias, podendo assim concluir que é possível sim envolver parte da população sobre 0 descarte de medicamentos de forma simples e barata, com implantações de urnas em locais de saúde pública. Sabe-se também que nem toda população foi afetada diretamente, porém os que frequentam a parte do serviço de saúde pública ao menos receberam a mensagem que os postos com urnas estão dispostos a coletar os medicamentos que não são mais usados.

Durante toda a pesquisa, preocupou-se primariamente com o meio ambiente e o impacto desse descarte sobre ele. Porém, no decorrer dos dias de pesquisa, notou-se que não se trata apenas de recolher medicamentos com a intenção de contribuir para o gerenciamento de resíduos, e sim de assegurar a saúde social, pois há possibilidade de ocorrer casos de intoxicações devido à ingestão de medicamentos já vencidos. Se isso ocorrer com 0 idoso, há risco de morte e provavelmente haverá gastos públicos elevados durante 0 tratamento, que será prologando.

A partir desta junção da pesquisa por parte ambiental e social, se conclui então que o descarte de medicamentos não é apenas uma campanha ambiental, é uma campanha que paralelamente atinge a sociedade inteira prevenindo possíveis acidentes, sendo algo além de uma própria consciência ambiental. Caracterizando-se como uma ação de impacto a curto prazo na prevenção de intoxicações e, ao mesmo tempo, uma ação de longo prazo contribuindo para a preservação da qualidade de nossos recursos naturais.

Por fim, considera-se que o presente projeto foi de extrema importância para a formação técnica dos alunos, e que esses cresceram no âmbito educacional, profissional e pessoal, tendo a oportunidade de conhecer leis e diretrizes técnicas de descarte, bem como de aprofundarse em uma questão plural e multifacetada que propiciou conhecimentos nos mais diversos âmbitos. Considera-se também que as colocações feitas durante 0 trabalho podem ser úteis ao crescimento da cidade, bem como à estruturação de um futuro projeto fixo que inclua o descarte de medicamentos vencidos na cidade de Jaraguá do Sul.

\section{Referência bibliográfica}

Agência Nacional de Vigilância Sanitária - ANVISA. RDC 33: Regulamento Técnico para 0 gerenciamento de resíduos de serviços de saúde. Brasil, 2003.

CALIXTO, João B.; SIQUEIRA, Jarbas M. Jr. Desenvolvimento de medicamentos no Brasil: Desafios. Florianópolis - SC, 2008. 
MONTE, Edmar Ferreira; FlLHO, José Carlos de Souza. Varejo de medicamentos no Brasil: Uma visão comparativa com a tendência mundial. São Paulo - SP, 1998.

HOPPE, Taís Raquel Grings; ARAÚJO, Luiz Ernani Bonesso de. Contaminação do Meio Ambiente pelo Descarte Inadequado de Medicamentos Vencidos ou Não Utilizados. Monografias Ambientais. REMOA / UFMG. nº 6 p.1248 - 1262, 2012.

BILA, Daniela Maia.; DEZOTTI, Márcia. Fármacos no meio ambiente. Química. Nova, 2003, v.26 n. 4, pp. 523-530.

World Health Organization. Antimicrobial resistance: global report on surveillance. França, 2014. Disponivel em: http://apps.who.int/iris/bitstream/10665/112642/1/9789241564748_ eng.pdf?ua=1. Acesso em: 20 de Setembro de 2015.

NAIME, Roberto; SARTOR, Ivone; Garcia Ana Cristina. Uma abordagem sobre a gestão de resíduos de serviços de saúde. Revista Espaço para a Saúde, Londrina, v. 5, n. 2, p. 17-27, jun. 2004.

Governo Federal Ministério do Meio Ambiente. Plano nacional de resíduos sólidos, versão preliminar para Consulta Pública, Brasília, 2011. Disponível em: <http://www.mma.gov. br/estruturas/253/_publicacao/253_publicaca002022012041757.pdf > acesso em 17 de novembro de 2012.

BERNARDO, Carolini Teza. Elaboração do plano de gerenciamento de resíduos de serviços de saúde da farmácia solidária. Criciúma, 2009.

AZEVEDO, Mila. Apresentação e análise dos programas de tratamento dos resíduos sólidos do município de Curitiba. Curtiba, 2001.

JOÃO, Walter da Silva Jorge. Descarte de Medicamentos. Pharmacia Brasileira, $\mathrm{n}^{0} 82$ Junho/Julho/Agosto 2011 p. $14-16$.

\section{Agradecimentos}

Queremos agradecer principalmente à aluna Adelli Saramento Lentz, que participou de toda a execução desse projeto, do início ao fim, o aluno Augusto Felippe da Silva que participou da primeira parte, ao professor orientador, e todas as demais pessoas que ajudaram para que esse projeto fosse concluído. 0 nosso muito obrigado. 